\title{
Um Estudo sobre o Vocabulário Religioso Utilizado por Evangélicos Usuários de CAPS
}

\author{
Halline Iale Barros Henriques ${ }^{1}$ \\ Pedro de Oliveira Filho ${ }^{2}$ \\ ${ }^{1}$ Centro Universitário do Vale do Ipojuca, PE, Brasil. $\quad{ }^{2}$ Universidade Federal de Campina Grande, PB, Brasil. \\ Alessandra Aniceto Ferreira de Figueirêdo ${ }^{3}$ \\ ${ }^{3}$ Universidade do Estado do Rio de Janeiro, RJ, Brasil.
}

Resumo: Esta pesquisa objetivou analisar o vocabulário religioso utilizado por evangélicos usuários de CAPS da cidade de Campina Grande (PB). Trata-se de uma pesquisa qualitativa, tendo como base teórico-metodológica a abordagem da Psicologia Social Discursiva. Para tanto, foram realizadas oito entrevistas narrativas e uma roda de conversa. Os entrevistados falaram das guerras contra o mal, da glossolalia, do gozo espiritual com Deus, bem como da peregrinação de pessoas na busca pela oração nas igrejas, com o objetivo de resolver os problemas do mundo. Os participantes também exploraram em seu vocabulário descrições de Deus e utilizaram expressões que faziam referência à conversão, ao desvio e ao testemunho. Considera-se que o discurso religioso atua sobre os usuários como poder disciplinar, agindo sobre seus corpos, adestrando seus gestos, regulando seus comportamentos, com o objetivo de separar, comparar, distribuir, hierarquizar e categorizar as pessoas, diferenciando aqueles que alcançarão a salvação dos que seguem as "coisas do mundo".

Palavras-chave: Práticas Religiosas, Retórica, Discurso.

\section{A Study about Religious Vocabulary used by Evangelical CAPS Users}

\begin{abstract}
This research was aimed at analyzing the religious vocabulary used by evangelical CAPS users in the city of Campina Grande-PB. This was a qualitative research, based on the theoretical-methodological approach of Discursive Social Psychology. In order to collect data, eight personal interviews and one discussion were conducted. Respondents spoke of the wars against evil, glossolalia, the spiritual enjoyment of God, as well as the pilgrimage of people to various churches, in order to solve the problems of the world. Participants also explored descriptions of God and used expressions that referred to conversion, deviation and testimony. It was considered that the religious discourse acts as a disciplinary measure, regulating one's behaviors, gestures and body with the objective of separating, comparing, distributing, hierarchizing and categorizing people, differentiating those who will achieve salvation with those who follow the "things of the world".
\end{abstract}

Keywords: Religious Practices, Rhetoric, Discourse. 


\title{
Un Estudio sobre el Vocabulario Religioso Utilizado por Evangélicos Usuarios del CAPS
}

\begin{abstract}
Resumen: Esta investigación objetivó analizar el vocabulario religioso utilizado por evangélicos usuarios de CAPS de la ciudad de Campina Grande-PB. Se trata de una investigación cualitativa, teniendo como base teórico-metodológica el abordaje de la Psicología Social Discursiva. Para ello, se realizaron ocho entrevistas narrativas y una rueda de conversación. Los entrevistados hablaron de las guerras contra el mal, la glossolalia, el gozo espiritual con Dios, así como la peregrinación de personas en la búsqueda de la oración en las iglesias, con el objetivo de resolver los problemas del mundo. Los participantes también exploraron en su vocabulario descripciones de Dios y utilizaron expresiones que hacían referencia a la conversión, al desvío y al testimonio. Se considera que el discurso religioso actúa sobre los usuarios como poder disciplinario, actuando sobre sus cuerpos, adiestrando sus gestos, regulando sus comportamientos, con el objetivo de separar, comparar, distribuir, jerarquizar y categorizar a las personas, diferenciando a aquellos que alcanzarán la salvación de los que siguen las "cosas del mundo".
\end{abstract}

Palabras clave: Prácticas Religiosas, Retorica, Discurso.

\section{Introdução}

A religião está frequentemente incluída nas crenças e experiências de pessoas em sofrimento psíquico, uma vez que os sujeitos buscam tratamentos espirituais para obter a cura de seus males, através de rituais religiosos, fazendo uso de unções, correntes, bênçãos e dízimo, como destacam Santos, Koller e Pereira (2004).

Crescem cada vez mais instituições no meio pentecostal (igrejas pentecostais e neopentecostais) de caráter terapêutico com práticas propriamente religiosas, como oração e doutrinação, que oferecem cura ao sofrimento psíquico, conduzindo uma demanda que é potencializada pela experiência da fé, por um lado, e por imperativos éticos por outro, limitando e moldando as condições para o processo de subjetivação do fiel (Próchino, Paradivini, \& Gonçalves, 2008).

Mariano (2011) faz uma distinção entre as igrejas pentecostais clássicas e as igrejas neopentecostais; as primeiras conservariam doutrinas mais rígidas quanto aos costumes e comportamentos dos fiéis, enquanto que as últimas apresentariam como características: a exacerbação da guerra espiritual contra o Diabo, na tentativa de combater os problemas que acometem os milhares de fiéis; a pregação da Teologia da Prosperidade, tendo como foco crenças relacionadas à cura, à prosperidade e à fé; a liberalização no que diz respeito aos costumes e comportamentos dos fiéis e o empreendedorismo econômico nas igrejas.

$\mathrm{O}$ referido autor afirma que as igrejas neopentecostais caminham para um processo que ele chama de "mundialização", tendo em vista que essas igrejas se mostram menos sectárias em sua relação com o mundo do que as igrejas que as precederam.

O neopentecostalismo desvaloriza o discurso teológico que prega o sofrimento e valoriza ideais de consumo, prosperidade e ascensão social. Em contrapartida, continua adotando o dualismo Deus-Diabo em seus processos ritualísticos, com objetivo de que o fiel vença o mal para obter saúde e sucessos terrenos (Santos, 2006).

Esta ideia é difundida por várias igrejas evangélicas, que se utilizam de um vocabulário religioso, o qual traz consigo o slogan da "libertação de pessoas endemoniadas", fazendo uso de metáforas de guerra (como "guerra santa", "soldados", "batalha", "lutas", "munição", "perigo", "resistência", "castigo", "destruição", "vitória", "derrota", dentre outras), que tornam semelhantes a luta contra o demônio e uma guerra real (Santos et al., 2004, p. 87).

É sobre o vocabulário religioso evangélico, utilizado por usuários de Centros de Atenção Psicossocial $(\mathrm{CAPS})^{1}$ da cidade de Campina Grande (PB) que este

\footnotetext{
${ }^{1}$ A pesquisa em questão foi realizada em Centros de Atenção Psicossocial, uma vez que procurou-se entender o vocabulário religioso utilizado em discursos de evangélicos nesses serviços. Este estudo é oriundo da dissertação de Mestrado da autora, intitulada: “Igreja e serviço de saúde mental: um estudo das narrativas de evangélicos, usuários de CAPS” (Henriques, 2012).
} 
estudo irá se debruçar a partir do referencial teórico-metodológico da Psicologia Social Discursiva.

A Psicologia Social Discursiva originou-se de uma vertente específica de análise de discurso, desenvolvida na Psicologia Social na década de 1980. Porém, é na década de 1990 que ela se constrói fora da análise de discurso. Por um lado, na tentativa de distinguir-se de outras formas de análise do discurso e, por outro, para tentar reestruturar o próprio objeto de estudo da Psicologia Social (Camino, Pereira, Lima \& Torres, 2013).

Essa abordagem se constituiu fundamentalmente a partir da obra Discourse and Social Psychology: beyond attitudes and behaviour, publicada em 1987 por Jonathan Potter e Margaret Wetherell (Potter, \& Wetherell, 1987). Tal obra é tida como pioneira no estudo do discurso em Psicologia Social.

Os teóricos da Psicologia Social Discursiva interessam-se pela função do discurso, pelo modo realizamos ações com nossas descrições e construímos a realidade com seus diferentes sujeitos e objetos (Potter, 1998).

O termo construção, nessa perspectiva, serve para afirmar que a nossa relação com o mundo não é direta, que ela se dá por intermédio de construções discursivas (Potter, \& Wetherell, 1987).

Paralelamente ao crescimento da Psicologia Social Discursiva, os anos 1980 viram também a emergência de estudos sobre a retórica na Psicologia Social. Michael Billig (Billig, 2008) é considerado um teórico de destaque neste campo com a obra Arguind and Thinking: a rethorical Approach to Social Psychology. Nesse estudo, o autor defende o uso das possibilidades analíticas da retórica na identificação dos tipos argumentativos, de figuras retóricas, enfim, de estilísticas que tornam o discurso persuasivo (Garay, Iñiguez, \& Martínez, 2005).

Nesse modo de compreender a retórica, o conflito é um elemento central da linguagem em uso e da vida em sociedade. De fato, quando as pessoas afirmam uma determinada posição sobre o mundo ou sobre si mesmas, geralmente elas respondem a posições contrárias que podem ser potenciais ou omitidas, ou que podem realmente estar presentes nas conversas circundantes (Nogueira, 2008; Billig, 2008).

Este estudo objetiva identificar o vocabulário mobilizado por evangélicos usuários de CAPS da cidade de Campina Grande, procurando compreender como é usado em argumentações favoráveis às versões de mundo presentes no universo religioso do qual fazem parte.

\section{Método}

Foram utilizados dois instrumentos metodológicos para a geração de dados: uma roda de conversa e oito entrevistas narrativas. $\mathrm{O}$ procedimento de geração dos dados ocorreu no período de fevereiro a abril de 2011. Participaram do estudo usuários que frequentavam os CAPS II e III da cidade de Campina Grande, que eram frequentadores de igrejas evangélicas e se dispuseram a contribuir com a pesquisa.

A roda de conversa se constituiu de nove pessoas, sendo cinco homens e quatro mulheres, com idades entre 32 e 50 anos para os homens e 17 e 33 anos para as mulheres. A partir da realização da roda de conversa é que foram selecionados os participantes da entrevista narrativa. As entrevistas foram feitas com oito participantes, sendo sete mulheres e um homem. $\mathrm{O}$ homem tinha 32 anos e a idade das mulheres variava entre 17 e 48 anos.

A quantidade de entrevistas e a roda de conversa realizada tomaram por base o critério de saturação. O ponto de saturação é a condição necessária para que se possa determinar o momento em que já se dispõe de informações suficientes sobre determinado aspecto (Fontanella et al., 2011).

As entrevistas foram audiogravadas, através de aparelho MP4. A roda foi audiogravada e filmada. O material coletado foi transcrito na íntegra e submetido à análise, tomando por base a perspectiva teórico-metodológica da Psicologia Social Discursiva.

Considerou-se os aspectos éticos, orientados pela Resolução no 196/1996 sobre pesquisa envolvendo seres humanos, bem como se primou pelo consentimento informado e o anonimato dos participantes. Obteve-se aprovação do Comitê de Ética da Universidade Estadual da Paraíba de número CAAE 0588.0.133.000-10.

\section{Resultados e discussão}

\section{Guerras contra o mal}

Nesta categoria, observou-se o conflito clássico entre o bem e o mal, representado respectivamente pelo céu e o inferno. De acordo com Mariano (2011), este embate entre os reinos celestiais e das trevas permeia todo o cristianismo e o próprio pentecostalismo 
clássico, sendo mais enfatizado no neopentecostalismo. Para o autor, a exacerbação da guerra espiritual contra o Diabo caracteriza-se nesse movimento religioso como um fator importante, transformando-se em uma tentativa de combate aos problemas que acometem os fiéis.

Santos (2006) aponta a ocorrência do dualismo Deus-Diabo nos processos ritualísticos do neopentecostalismo, destacando que o objetivo do fiel é vencer o Diabo para obter saúde e sucessos terrenos.

Os discursos de Rodrigo e Cícera ilustram bem as afirmações dos autores acima, ao falarem da relação entre Deus e o Diabo e da obediência às normas divinas como um meio de obter a salvação e de vencer a batalha travada entre o bem e o mal. O discurso de Rodrigo também se assemelha ao discurso de Lana, quando faz referência ao inferno como um lugar de castigo e ao céu como lugar abençoado.

Mas tem o servo e tem crente. Crer até o Satanás crê! Por que [...] Agora um servo serve mesmo ao Senhor, obedece à palavra dele. Tem que obedecer se quiser um dia morar no céu com ele (Cícera, Igreja Deus é Amor/Só Jesus Salva).

Se a pessoa olhe, a pessoa nesse mundo pode ser ela quem for se ela não seguir, se ela não seguir os passos de Jesus, ela segue que passos, me diga? Se ela for por outro caminho, que é o céu e o inferno, se ela não vai pelo caminho, ela vai pra onde, me diga aí? Não tem escapatória para aquela pessoa, né? Ela tem que decidir a vida dela. Porque ela morrendo, tem tanta gente morrendo aí sem Jesus, e aí? Essa alma vai pra onde? Num vai pro inferno? [pausa] Porque pra quem acredita nas almas, né? Mas elas vão pro inferno, vão pro inferno, num vão? Tem que procurar Jesus mesmo, né isso? Não será possível que num caso desse, num chegou nenhuma pessoa pra dizer: - Caminha aí oh? Caminha aí oh, vai! Ergue a tua fé, faz o que eu estou te dizendo, eu vou contigo, nós vamos juntos, tal [...] Vai só eu, a gente se encontra lá e tal. Mas a pessoa tem que ser obediente, sabe? Vixe [...] se não for não tem como ser abençoado não [...] (Rodrigo, Igreja Universal do Reino de Deus).

Aí, eu queria ele pra mim ou então morresse, como se eu morresse eu ia para o inferno ou se eu me matasse eu ia para o inferno e como eu não tinha coragem de me matar, então eu fui pedir ao inimigo para me dar ele, misericórdia!

Pesquisadora: Como foi esse encontro, quem era o inimigo?

Lana: O inimigo era o Diabo que a gente chama (Lana, Igreja Presbiteriana do Avivamento).

Observe-se que a palavra "inferno" sofre repetições, no discurso de Rodrigo e Lana, o que denota um efeito redundante, constituindo-se em um instrumento fundamental de intensificação emocional, que indica a importância dada pelo sujeito a essa questão, como aponta Cavallaro (1999). No discurso de Rodrigo, pode-se observar o uso de termos e metáforas ("seguir os passos de Jesus" e "ergue a tua fé") para caracterizar e avaliar ações de um crente fiel.

Já Lana faz uso de uma figura retórica como o eufemismo, ao substituir o termo "Diabo" pelo termo "inimigo". Esta também se refere ao inferno como um lugar povoado pelo mal, como um lugar de castigo, pois se a narradora matasse o namorado, ou provocasse a própria morte, habitaria o inferno.

Os pentecostais, bem como os neopentecostais de forma mais enfática, se apegam à crença no Diabo e em demônios como o grande inimigo para justificar os rituais exorcistas. De acordo com Mariano (2011), tais crenças e práticas são difundidas nos cultos através da exacerbação da guerra espiritual contra o Diabo, e da difusão da ideia de ação ilimitada do Diabo em todo e qualquer lugar e/ou coisa, bem como da invocação da manifestação de demônios.

No tocante à crença da ação ilimitada do Diabo/ demônios, o Missionário R.R. Soares (1984, p. 24, $83,85)$, televangelista brasileiro e fundador da Igreja Internacional da Graça de Deus, citado por Mariano (1999, p. 114), afirma que:

[...] não existe nada que esteja fora da ação demoníaca. No futebol, na política, nas artes e na religião, nada escapa ao cerco do Diabo [...]. Satanás tem milhares de agências no mundo [...]. Por trás da religião, do intelectualismo, da poesia, da arte, da música, da Psicologia, do entendimento humano e de tudo com o que temos contato, Satanás se esconde. 
Edir Macedo (1988, p. 89-98), conhecido como Bispo, televangelista, empresário e religioso brasileiro, fundador da Igreja Universal do Reino de Deus (IURD), e proprietário da Rede Record de Televisão, em um de seus livros, citado por Mariano (1999, p. 114), descreve os demônios como entidades que:

[...] fazem das pessoas o que bem entendem. Cuidam de todos os aspectos da vida delas, desde a maneira de se vestir até os casos amorosos; se intrometem e submetem os seus seguidores através de conselhos ou ameaças. Astuciosos, os demônios agem de acordo com a mentalidade da pessoa, de acordo com sua posição social e também, é claro, de acordo com as suas necessidades.

Pode-se perceber a aproximação de alguns pontos das citações acima com os discursos dos entrevistados, nelas o demônio/Diabo é construído como uma figura astuciosa e poderosa, atuando em todos os aspectos da vida do sujeito, além de estar em todos os lugares.

Cícera enfatiza a ação demoníaca em dois momentos de sua entrevista, um para falar da experiência do marido com o alcoolismo e outro quando menciona a experiência de uma usuária do CAPS com a tentativa de suicídio.

Assim [...] Convivi com meu esposo, ele bebia, bebia, né? Aí hoje em dia eu lembro que naquele tempo eu não era evangélica e eu ia reagir, né? [...] Eu ia assim tendo aquele choque quando ele chegava, né? Alcoolizado que ali na verdade não era ele, né? Hoje conhecendo a palavra do senhor eu sei que aquilo não é ele, né? Que ali é algo que se apodera da vida da pessoa, né? Para destruir a família, porque a família é um plano de Deus e o inimigo não quer, ele atua mais com a família hoje em dia, como eu conheço a verdade, né? Voltei para Jesus com um tempo, aí [...] Eu comecei, né? (Cícera, Igreja Deus é Amor/Só Jesus Salva).

Então, eu falei assim pra ela e ela disse: "porque Deus é tão injusto e não me deixa fazer [...] Tirar minha vida". Mas eu digo: "como é que Deus vai tirar sua vida se ele é o dono da vida! Ele até permite, sim! Se o inimigo sobe na sua carne, como já tocou várias vezes, né?” (Cícera, Igreja Deus é Amor/Só Jesus Salva).
No primeiro trecho, Cícera relata o domínio do demónio ("algo que se apodera da vida da pessoa") sobre o seu marido quando ele se encontra em estado de embriaguez, reproduzindo o sentido das palavras de Edir Macedo quando este se refere aos demônios como algo que se apossa não só do corpo, mas também da mente do sujeito, impossibilitando a sua autonomia. Estes discursos também se aproximam quando Cícera atribui ao "inimigo" a responsabilidade pela destruição da família, representando a família como um dos palcos principais da atuação do demónio na atualidade: "ele atua mais com a família hoje em dia".

Em outro momento, Cícera fala do poder do "inimigo" sobre o corpo de uma usuária, ou melhor, sobre a sua "carne". O tropo linguístico "o inimigo sobe na sua carne, como já tocou várias vezes” é de grande eficácia retórica ao transformar em uma imagem compreensível e dramática a ideia do poder do demónio sobre um ser humano.

O poder ilimitado conferido ao Diabo/inimigo também pode ser identificado nos discursos de Rodrigo e Lana:

Aí você sabe que o diabo é sujo, né? E de tanto o diabo ser sujo, eu to pensando numa coisa, você está pensando em outra [...]. Tem gente que fica invejando sabe? O que a gente tá conversando aqui, sabe aê? Nada a ver mulher, uma coisa com a outra. Nada a ver, porque o tanto de vez que eu já sofri nessa vida, pelo amor de Deus, não! [...] Assim, que muitas vezes na igreja estando errado as coisas, sabe aê? Aí isso [pausa] é ruim pra quem isso? Para o pastor não é não? Porque se, olhe, o pastor tem também que abrir os olhos, o diabo vai carregar ele e ele não sabe! Tá vendo como são as coisas? Não pode [...] não pode [...] Não pode um negócio desses, né? Tem que haver uma diferença, né? [pausa] (Rodrigo, Igreja Universal do Reino de Deus).

Me passou que eu precisava de autoridade sobre o inimigo e me defender com a Bíblia porque Deus tem o poder de decisão. Porque eu sempre soube que eu não precisava ter medo do inimigo, porque eu tenho poder de autoridade sobre ele, eu tenho mais poder do que ele, acredita? Se eu tiver na fé genuinamente forte, agora eu não tô forte, mas se eu tiver forte eu tenho mais poder do que ele! [...] 
Pesquisadora: Lana e quando você falou que um Pastor disse pra você que você tem o controle sobre o inimigo, né? O que é que você acha disso?

Lana: Não é controle é autoridade, é diferente! (Lana, Igreja Presbiteriana do Avivamento).

Rodrigo identifica a figura do Diabo através do adjetivo "sujo", construindo para ele uma identidade repulsiva e profundamente negativa. Em outro momento, o narrador se refere às consequências negativas para o pastor da igreja, caso alguma "coisa na igreja esteja errada”. Dessa forma, o pastor é quem é vitimizado, passando a receber o castigo. A metáfora "o diabo vai carregar ele e ele não sabe!" mais uma vez reitera a ideia do poder ilimitado do Diabo.

A expressão "o diabo vai carregar ele e ele não sabe!" fundamenta outra preocupação do fiel, a de que o pastor tem que seguir os planos de Deus, pois se assim o fizer não sairá "nada de errado" na igreja. Essa preocupação é intensificada com o imperativo "não pode!" repetido por três vezes. No seu relato, o pecado do pastor é mais condenável do que o pecado de um seguidor comum; é inadmissível para os seus seguidores.

No sentido oposto dos relatos anteriores, no relato de Lana constrói-se o poder e a autoridade de um fiel sobre o inimigo, quando ela afirma que, para ter "autoridade" sobre o "inimigo", é preciso ter uma fé genuína que torna o crente suficientemente forte para derrotar o inimigo. É preciso estar preparado e forte para enfrentar um adversário tão perigoso, ativo e poderoso; é desse modo que os "fiéis são convidados a alistar-se como soldados nas tropas do Senhor dos Exércitos," como bem coloca Mariano (1999, p. 114).

Nesse modo de compreender o mundo, os "exércitos do Senhor" precisam estar guarnidos de poder para o dia do "Juízo Final", o dia da vitória do bem contra o mal, quando os "convertidos serão arrebatados por Deus" e o povo será "remido e lavado pelo sangue dele", conforme descreve Cícera:

[...] você sabe que tudo aqui é passageiro, mas que um dia tudo vai acabar. Jesus vai vir buscar o povo dele, a igreja, e [...] O povo remido e lavado pelo sangue dele, porque todo mundo diz: Não Jesus não vem não! Jesus vem sim! Um dia Jesus vai descer aqui, ele não vai descer mais na terra, ele vai ficar nas nuvens e vai arrebatar cada um daqueles que servir a ele, em espírito e verdade. Tá entendendo? Ele fez promessa que foi preparar lugar pra um dia vir buscar nós. Pronto! Eu acho assim. (Cícera, Igreja Deus é Amor/Só Jesus Salva).

Neste discurso, a fiel se apresenta como alguém plenamente convencida da vitória final do bem contra mal. Em seu relato ela combate os descrentes que não acreditam na vinda de Jesus ("Jesus vem sim!") e constrói imagens poderosas para retratar o grande momento: "ele não vai descer mais na terra, ele vai ficar nas nuvens e vai arrebatar cada um daqueles que servir a ele, em espírito e verdade".

Sabe-se que as expressões e os elementos próprios das religiões afro-brasileiras são incorporados na crença, lógica e visão de mundo das igrejas neopentecostais. Marisa Soares (1990, p. 87), citada por Mariano (1999, p.127), revela que "ao invocar os demônios para que se apresentem sob a forma de caboclos, pretos-velhos etc., os pastores 'acatam' todo o panteão afro-brasileiro: falam com eles, dão credibilidade a sua existência”.

Pode-se exemplificar a reprodução desta incorporação pelos fiéis, no trecho a seguir, em que Rodrigo fala sobre a entidade "Caboclo Lino" e usa expressões como "mandar se fechar" e "manifestar de novo contra ele”, características das religiões afro-brasileiras:

[...] é porque muitos pastores já ouviram falar que tem pessoas que é batizada no espírito santo que, não é o espírito santo que está usando ela para falar aquilo, é o espírito maligno, o caboclo Lino, né? Chamado cCaboclo Lino, né?

\section{Pesquisadora: Como?}

Rodrigo: Caboclo Lino! Sabe aê? Deixando as pessoas serem enganadas pelo aquele espírito, sabe? Aí o pastor vem e manda logo parar, sabe aquela pessoa logo? Manda se fechar logo e (inaudível) Aí manifesta de novo contra ele, sabe aê? Tem que ser a pura verdade, aquilo que você está pensando, tem que ser aquilo que você está querendo, né isso? No momento, né? Aí sabe se a pessoa tá usando o espírito santo mesmo ou não, sabe aê? Entendeu aê? (Rodrigo, Igreja Universal do Reino de Deus). 
A referência ao "Caboclo Lino" e o uso de expressões como "mandar se fechar" e "manifestar de novo contra ele", próprias da religião da Umbanda, no discurso de um iurdiano remete ao conceito de bricolagem utilizado por Lévi-Strauss (1967), citado por Galinkin (2008), que evidencia a utilização de expressões ou elementos próprios de outros contextos religiosos para falar, nesse caso, da existência do "espírito maligno".

O discurso de Rodrigo é convergente com a afirmação de Edir Macedo (1985, p.101) citado por Mariano (1999, p. 126) quando este afirma: "Temos tido contato com inúmeras pessoas que pensam ter sido batizadas com o Espírito Santo, quando na verdade estão possuídas por um exu, ou um caboclo qualquer".

\section{O gozo e o falar em línguas nas igrejas quentes: as especificidades do vocabulário pentecostal}

Nem todos os discursos dos entrevistados giram em torno da guerra contra o mal. Eles também falam na glossolalia, no gozo espiritual com Deus, bem como na peregrinação de pessoas na busca pela oração, com o objetivo de resolver os problemas do mundo.

Eu acho que é uma situação tempestiva, né? Porque a palavra de Deus diz: - "Não tereis aflições, eu venci e vós vencerás!” Isso diz que taí o mundo cheio de problemas, as pessoas, muitas pessoas indo buscar a Deus em oração, quer levar a vida do jeito que a vida é que a vida não é, não é realmente, é uma luta constante de problemas que nós temos aqui na terra (Ismael, Igreja Pentecostal Nova Canaã).

Tem a Congregacional bem pertinho lá de casa, mas eu não gosto, mas só que não gosto, só gosto se for igreja de fogo. Se tiver fogo que (inaudível).

Pesquisadora: Qual é a diferença?

Lila: Porque a igreja é morna, igreja fria. A congregacional não tem aquele movimento que a Assembleia de Deus tem. O poço de Jacó. É totalmente diferente.

Pesquisadora: O que essas outras igrejas têm que a Congregacional não tem?
Lila: Fala em línguas. Que fala em línguas e é fogo. [silêncio] E essa igreja não é.

Pesquisadora: Como é esse fogo que você fala [...]

Lila: É [...] É uma alegria. É um gozo que vem de dentro da pessoa. Que a pessoa começa a adorar o Senhor começa a falar em línguas, nos mistérios. Só com Deus. Aí tem gente que vê e fica criticando, mas não é. É a língua de Deus, entendeu? (Lila, Cristã Presbiteriana).

No discurso de fiéis pentecostais, como por exemplo, no de Ismael, seguidor da Igreja Pentecostal Nova Canaã, a situação de enfrentamento/luta não é colocada de forma direta com o Diabo/Demônios, como nos discursos de fiéis neopentecostais. Pode-se perceber esta distinção quando Ismael descreve uma experiência conflitiva sem destacar o Diabo como o causador, sem mencionar o seu nome em nenhum momento da entrevista, contrariamente aos neopentecostais.

Outra prática comum e antiga aos evangélicos pentecostais foi verificada no discurso de um dos entrevistados, a glossolalia, ou melhor, o falar em línguas estranhas. Trata-se de um ritual evidenciado durante o batismo no Espírito Santo, como retrata Rodrigo em um discurso anterior. No discurso de Lila, percebe-se essa prática associada não ao batismo, mas aos tipos de igreja que proporcionam essa experiência.

Além do sentido literal da palavra fogo, a entrevistada emprega-o para se referir a um momento de alegria e gozo interior, que só é permitido por Deus. Esse elemento, o fogo, seria próprio das igrejas citadas pela narradora, pois utiliza esse termo para identificar a temperatura/intensidade do seu estado de alegria e de contato com a experiência divina, pois existem igrejas "frias, mornas e quentes".

\section{Descrições de Deus}

Nas falas dos entrevistados também se fizeram presentes descrições de Deus como a figura fundamental na vida desses sujeitos.

Deus é muito fiel, Deus faz, Deus mostra! Deus faz como ele quer, na hora certa e no tempo certo! [...] o que importa é a pessoa ter Deus no coração! 
Ter fé em Deus, porque sem Deus a gente não é ninguém, a gente não é ninguém! A gente é como um grãozinho de areia, como a areia da praia [...] Bom, que [pausa] não importa qual problema que a gente esteja passando, a gente tem um Deus que é maior que tudo isso, que é forte, e que é verdadeiro, e que é fiel! Então como eu falei, não há luta, não há batalha, vá à frente! Não esqueça de lutar porque ele já lutou por nós! E está tudo vencido, graças a Deus! Basta confiar em Deus! [...] tudo é providência de Deus, nada acontece ao acaso, tudo acontece na hora certa, Deus não permite que caia uma folha de uma árvore sem que seja à vontade dele. Então se a gente glorifica o nome dele é porque é da vontade dele e ele está presente (Lila, Cristã Presbiteriana).

Mas como eu creio em um Deus assim que ele cria situações na sua vida, ele cria situações na sua vida que a gente não entende hoje, mas amanhã é que você vai entender como Deus é maravilhoso, ele cuida de nós, e para cada criatura ele tem um plano, salvação! Né? [...] Que sem ele você não é nada! Sem Deus, nada [...] Porque Deus é Deus! Deus tem poder! [...] Porque nós sabemos que Deus é o Deus do impossível e ele é o médico dos médicos [...] um dia que eu tenho essa esperança, esperança não, eu tenho a certeza, porque ele prometeu que ia preparar lugar para nós. $\mathrm{E}$ confiando na palavra dele, Deus não mente! [...] Então eu creio num Deus assim [...] Que revela, ele mostra, ele não quer ver você [...] Ele avisa, ele avisa antes! Eu creio num Deus assim, ele avisa, ele não deixa ninguém enganado. Antes, ele manda avisar. Creio assim [...] [silêncio] (Cícera, Igreja Deus é Amor/Só Jesus Salva).

Deus te dá poder, você pede:- “Deus me dá poder, coloca poder nas minhas mãos agora e retira todo o mal que há em mim! Pelo poder de Deus e em nome de Jesus Cristo!” Pronto eu fiz isso! (Lana, Igreja Presbiteriana do Avivamento).

Na fala de Lila, a importância de Deus é acentuada por meio da obsessiva repetição do nome sagrado (12 vezes). Ela descreve Deus como "forte", "verdadeiro" e "fiel", e hiperbolicamente como algo "maior do que tudo". Em sua fala "o crente" é alguém desprovido de autonomia e determinação: "sem Deus a gente não é ninguém, a gente não é ninguém!". Conforme Cecília Mariz (1994, p. 66-67): "Os pentecostais [...] não veem o indivíduo como um ser autônomo. Todos dependem de Deus, sem o qual se tornam vítimas das forças malignas [...]. O pentecostalismo não abraça uma visão individualista já que não define o indivíduo como ser totalmente autônomo e determinado".

Essa compreensão também está presente no discurso de Cícera, através da expressão "sem ele você não é nada!", enfatizando a falta de autonomia e a necessidade/obrigatoriedade da fé em Deus para sua própria existência, reafirmado com a complementação: "sem Deus, nada [...]”. As características de ser maravilhoso, cuidador e mentor de um plano particular de salvação para cada fiel são atribuídas a Deus no discurso da entrevistada. Outras características são relacionadas a Deus, como: poderoso, sincero, revelador de caminhos, um ser que "não deixa ninguém enganado", por mais que o fiel só descubra e entenda os "planos de Deus" posteriormente às "situações criadas".

O discurso de Lila ilustra a afirmação de Mariano (2011) no tocante ao poder conferido ao divino pelos fiéis dessas igrejas. O divino estaria presente em todos os acontecimentos da vida humana, para cada evento vivido pelo fiel, haveria uma resposta nos textos bíblicos.

Lila refere-se exatamente à inexistência do acaso em seu discurso, justificando que "tudo" carece de explicações e vontades divinas, pois como a mesma diz até mesmo o cair de uma folha obedece à lógica divina.

\section{O uso das expressões: "aceitei Jesus", "estar convertido", "coisas do mundo", "desviar" e "testemunho"}

Essas expressões merecem destaque devido ao número de vezes em que elas aparecem nos discursos dos entrevistados, além de se constituírem como vocábulos comuns aos religiosos, tanto pentecostais quanto neopentecostais.

Os narradores utilizam a expressão "Aceitei Jesus" para falar do ingresso na religião: "Eu [...] Mais ou menos [...] Se não me falha a memória, eu acho que aceitei Jesus eu tinha, se eu não estou enganada eu tinha 33 anos [...]" (Josefa, Assembleia de Deus).

Então ser evangélica para mim é uma benção de Deus, porque antes eu era cega, eu entendia não sei [...] A verdade. Porque hoje eu chego ao 
Senhor e eu sei que ele vive em mim e um dia, eu creio que eu já estou salva. Assim, eu sou salva, por quê? Porque aceitei Jesus, deixei tudo do mundo, não vivo mais nas coisas do mundo, vivo no mundo, mas é mesmo que não viver que tem muitas coisas que eu era, eu era uma pessoa muito diferente! Assim [...] Eu mudei muito [...] Porque quando você aceitou Jesus você é separado. Você não vai mais roubar, se você bebia você não vai mais beber. É Deus é quem manda na sua vida! Somos todos filhos de Deus, somos sim. Mas há uma diferença entre quem serve e quem não serve a Deus, por quê? Porque quando você passa a ter uma intimidade com Deus, deixa as coisas do mundo, que não agrada a Deus de lado. Não que [...] todos somos filhos de Deus (Cícera, Igreja Deus é Amor/Só Jesus Salva).

Nesses relatos, aceitar Jesus é um passaporte para uma nova vida, é o acesso a uma verdade que promove uma transformação radical do sujeito. Cícera, filiada à Igreja Deus é Amor, considerada uma igreja pentecostal, faz uma distinção entre o mundo dentro da igreja e o mundo fora da igreja, mas essa distinção não é mais tão forte quanto em décadas anteriores uma vez que tem se intensificado uma liberalização dos usos e costumes nos espaços evangélicos de uma forma geral, especialmente entre os neopentecostais.

O termo "coisas do mundo", utilizado por Cícera no trecho acima, é empregado por Lila no trecho abaixo (com formas ligeiramente diferentes) para se referir à aceitação de Jesus e o afastamento de pessoas que estejam fora de seu contexto religioso, pois a amizade com essas pessoas a levaria para o mal, afastando-a da salvação.

Não saio para canto nenhum. Eu não vou pra canto nenhum, pra casa de amiga não. Porque se eu for atrás das minhas amigas vão me botar no mundo de novo e eu não quero mais.

Pesquisadora: O que é ficar no mundo pra você?

Lila: Assim [...] Participar do mundo, beber [...] Farrar [...] Ir pra festa [...] Ir pra show [...] Essas coisas.

Lila: Hoje em dia é totalmente diferente, hoje eu não saio com amiga, não tenho amigas, hoje eu não procuro ter amizades. Amizades com gente desconhecido. Só quero amizade que me influencie pro bem e não pro mal (Lila, Cristã Presbiteriana).

O sentido atribuído ao "mundo" para os pentecostais está atrelado, na maior parte das vezes, a sentimentos relacionados à rejeição, repúdio, correlacionado a uma autovigilância contínua. A esse respeito, Mariano (1999, p. 190) acrescenta que cumprir com o "Plano de Deus" acarreta certas "privações”, assim:

Para que não sucumbam às pulsões, aos desejos, às próprias inclinações pecaminosas, devem renunciar aos prazeres mundanos, compreendidos como ciladas do Diabo, por meio do padecimento e da modificação da carne. Para que o Espírito Santo lhes preencha a vida, santificando-os, devem morrer para o mundo, o qual, como causa e lugar de sofrimento, além de rejeitado, deve ser combatido. Quanto mais sectária a denominação, maior sua disposição de se apartar do mundo e combatê-lo.

"Estar convertido" se constitui como pré-requisito de demonstração de fé e de aceitação de Jesus, enquanto "desviar" significa pouca fé.

E tem pessoas na minha família que não são convertidas, sabe? Mas vamos ter fé em Deus, né? Fé em Deus. Com fé em Deus a pessoa chega lá, né? Você num tá confiando em Deus, né? Tudo pode naquele que crer, né? (Rodrigo, Igreja Universal do Reino de Deus).

Eu acho que você tem que se converter, Jesus manda, né? Na palavra dele, se converter dos seus maus caminhos e ele perdoa você, os pecados e a partir daquele momento você começa seguir Jesus [...] (Cícera, Igreja Deus é Amor/Só Jesus Salva).

Quando eu era pequena sempre frequentava [pausa] aí depois eu me desviei e agora voltei!

Pesquisadora: E Lana, me conta assim o que é esse desviar que você coloca?

Lana: É não ir mais, deixar de ser evangélico. 
Pesquisadora: É somente deixar de frequentar? Ou é deixar [...]

Lana: Tudo! (Lana, Igreja Presbiteriana do Avivamento).

Para Cícera, "se converter" é obter o perdão dos pecados cometidos e a segurança de caminhar em bons caminhos. A esse respeito, Valle (2010) acrescenta que as intervenções divinas não concedidas aos sujeitos são interpretadas como sinais de pecado, moral defeituosa e falta de fé.

O termo "testemunho" aparece nos discursos dos entrevistados nomeando uma prática necessária e constitutiva da fé. Trata-se, em outras palavras, de depoimentos de experiências, na maioria das vezes, sendo conquistadas por esses fiéis.

Hoje eu fui para a igreja, fazia tempo que eu tinha ido e minha tia disse que eu tinha um propósito, que Deus tinha um propósito por ter me colocado aqui no CAPS. Deus enviou você com essa entrevista, que na verdade é um testemunho, parte do meu testemunho (Lana, Igreja Presbiteriana do Avivamento).

Ah [...] Eu senti [...] Contei até o testemunho na igreja, para edificar a fé do irmão. Porque o que Deus faz tem que ser falado aos quatro cantos do mundo. Pra edificar o quê? A sua fé, que às vezes está um pouco oca, né? [...] O testemunho é você [...] Chegar [...] Por exemplo, você chegar na minha casa e diz: ah eu to com uma dor aqui! Ore aqui por mim irmã! [...] Eu fui revelada na igreja que [...] Tudo [...] O que ia acontecer [pausa] comigo o Senhor me revelava antes. É verdade! Eu digo a você porque eu tenho testemunho, assim [...] Que já aconteceu isso do mesmo jeito acontece. Do jeito que o Senhor falou. O que Deus fez na minha vida porque ele fez e tem que ser divulgado pra o mundo inteiro (Cícera, Igreja Deus é Amor/Só Jesus Salva).

Além de descrever as graças concedidas, o testemunho assume a função de revelar o inexplicável. Sendo necessário testemunhar às pessoas da igreja, situações conflitivas e o desfecho destas, o que acaba por caracterizar o controle que as pessoas da igreja exercem umas sobre as outras, firmando mais uma vez a relação de vigilância contínua sobre os acontecimentos cotidianos da vida das pessoas, logo testemunhar as obras de Deus acaba por fazer parte desse controle.

A vigilância contínua nesses espaços pode ser melhor compreendida a partir do conceito de disciplina, utilizado por Foucault (2015), o qual enfatiza que a disciplina é uma técnica de poder que implica uma vigilância perpétua e constante sobre os sujeitos, através dela, a vida das pessoas pode ser gerida. Essa técnica de poder requer um registro contínuo de observações sobre os sujeitos, registro esse que não pode deixar escapar nenhum detalhe, ou acontecimento sobre a pessoa observada. Isso pode ser observado nos testemunhos, realizados pelos fiéis no momento em que eles detalham a graça alcançada e o que foi preciso fazer para alcança-la, enredando os outros fiéis em teias de significados com inequívoca capacidade persuasão e de controle.

\section{Considerações finais}

Os discursos dos entrevistados apresentaram a relação entre Deus e o Diabo e a obediência às normas divinas como meio de se obter a salvação e de vencer a batalha travada entre o bem e o mal.

O demônio/Diabo é construído como uma figura astuciosa e poderosa, que atua em todos os aspectos da vida do sujeito, além de estar em todos os lugares. O uso da palavra "inimigo" para descrevê-lo e a identificação do mesmo através do adjetivo "sujo", constrói para essa figura uma identidade repulsiva e profundamente negativa, com poder e autoridade sobre a vida dos sujeitos. Todavia, a autoridade sobre o "inimigo" também é colocada como possibilidade mediante a existência da fé genuína, que tornaria o crente suficientemente forte para derrota-lo.

No discurso de fiéis pentecostais, a situação de enfrentamento/luta não é colocada de forma direta com o Diabo/Demônios, como nos discursos de fiéis neopentecostais. Eles falam ainda na glossolalia, no gozo espiritual com Deus, bem como na peregrinação de pessoas na busca pela oração, com o objetivo de resolver os problemas do mundo.

Foram observadas, ainda, descrições de Deus como a figura fundamental na vida dos entrevistados, sendo caracterizado como figura "forte", "verdadeira" e "fiel", e hiperbolicamente como algo "maior do que tudo". Tal compreensão também enfatiza a relação de falta de autonomia e a necessidade/obrigatoriedade da fé em Deus para a própria existência do sujeito. 
Uso de expressões como: "aceitar Jesus" e "coisas do mundo" aparecem nos discursos dos entrevistados. "Aceitar Jesus" carrega consigo o movimento de transformação radical do sujeito e o afastamento de pessoas que estejam fora de seu contexto religioso, o que caracterizaria as "coisas do mundo", as quais levariam a pessoa para o mal e a afastaria da salvação.

O sentido atribuído ao "mundo" para os pentecostais está atrelado, na maior parte das vezes, a sentimentos relacionados à rejeição, repúdio, correlacionado a uma autovigilância contínua. Já o termo "testemunho" aparece nos discursos dos entrevistados nomeando uma prática necessária e constitutiva da fé. Trata-se de depoimentos de experiências, na maioria das vezes, conquistadas por esses fiéis. Além de descrever as graças concedidas, o testemunho assume a função de revelar o inexplicável. Sendo necessário testemunhar às pessoas da igreja, situações conflitivas e o desfecho destas, o que acaba por caracterizar o controle que as pessoas da igreja exercem umas sobre as outras.

Nos relatos dos participantes, a compreensão religiosa do mundo que eles abraçaram parece atuar sobre eles como um dispositivo disciplinar que age sobre seus corpos, adestra seus gestos e regula seus comportamentos. Um dispositivo que separa, compara, distribui, hierarquiza e categoriza as pessoas, diferenciando aqueles que alcançarão a salvação dos que seguem as "coisas do mundo".

\section{Referências}

Billig, M. (2008). Argumentando e pensando: Uma abordagem retórica à psicologia social. Petrópolis, RJ: Vozes.

Camino, L., Pereira, M. E., Lima, M. E. O., \& Torres, A. R. R. (Orgs.). (2013). Psicologia social: Temas e teorias. Brasília, DF: TechnoPolitik.

Cavallaro, R. (1999). Storie senza storia: Indagine sull'emigrazione calabrese in GranBretagna (2a ed.). Roma: Centro Studi Emigrazione.

Fontanella, B. J. B., Luchesi, B. M., Saidel, M. G. B., Ricas, J., Turato, E. R., \& Melo, D. G. (2011). Amostragem em pesquisas qualitativas: Proposta de procedimentos para constatar saturação teórica. Cadernos de Saúde Pública, 27(2), 389-394. https://doi.org/10.1590/S0102-311X2011000200020

Foucault, M. (2015). Vigiar e punir: Nascimento da prisão. Rio de Janeiro, RJ: Vozes.

Galinkin, A. L. (2008). A cura no vale do amanhecer. Brasília, DF: TechnoPolitic.

Garay, A., Iñiguez, L., \& Martínez, L. M. (2005). La perspectiva discursiva en psicología social. Subjetividad y Procesos Cognitivos, (7), 105-130.

Henriques, H. I. B. (2012). Igreja e serviço de saúde mental: Um estudo das narrativas de evangélicos, usuários de CAPS (Dissertação de Mestrado). Programa de Pós-Graduação em Psicologia, Universidade Federal de Pernambuco, Recife, PE.

Mariano, R. (1999). Neopentecostais: Sociologia do novo pentecostalismo no Brasil. São Paulo, SP: Loyola.

Mariano, R. (2011). Sociologia do crescimento pentecostal no Brasil: Um balanço. Perspectiva Teológica, 43(119), 11-36.

Mariz, C. (1994). Libertação e ética: Uma análise do discurso de pentecostais que se recuperaram do alcoolismo. In: A. Antoniazzi, Nem anjos nem demônios: Interpretações sociológicas do pentecostalismo (pp. 204-224). Petrópolis, RJ: Vozes.

Nogueira, C. (2008). Análise(s) do discurso: Diferentes concepções na prática de pesquisa em psicologia social. Psicologia: Teoria e Pesquisa, 24(2), 235-242. https://doi.org/10.1590/S0102-37722008000200014

Potter, J. (1998). La representación de la realidad: Discurso, retórica y construcción social. Buenos Aires: Paidós.

Potter, J., \&Wetherell, M. (1987). Discourse and social psychology: Beyond attitudes and behaviour. London: Sage.

Próchino, C. C. S. C., Paradivini, J. L. L., \& Gonçalves, M. A. (2008). Subjetivação e cura no neopentecostalismo. Psicologia: Ciência e Profissão, 28(3), 586-601. https:// doi.org/10.1590/S1414-98932008000300012

Santos, A. M. V. (2006). Sofrimento psíquico e neopentacostalismo: A identidade religiosa e a cura na sociedade do consumo e do espetáculo (Dissertação de Mestrado). Universidade Federal do Rio de Janeiro, Rio de Janeiro, RJ. 
Santos, E. C., Koller, S. H., \& Pereira, M. T. L. N. (2004). Religião, saúde e cura: Um estudo entre neopentecostais. Psicologia: Ciência e Profissão, 24(3), 82-91. https://doi.org/10.1590/S1414-98932004000300011

Valle, E. (2010). Psicologia e experiência religiosa. São Paulo, SP: Loyola.

\section{Halline Iale Barros Henriques}

Professora do Centro Universitário do Vale do Ipojuca (UNIFAVIP/Devry), Caruaru - PE. Brasil. Mestre em Psicologia pela Universidade Federal de Pernambuco (UFPE), Recife - PE. Brasil. E-mail: hallineiale@hotmail.com

(iD https://orcid.org/0000-0001-8428-9072

Pedro de Oliveira Filho

Professor Associado I da Universidade Federal de Campina Grande (UFCG), Campina Grande - PB. Brasil. Colaborador no Programa de Pós-Graduação em Psicologia da Universidade Federal de Pernambuco (UFPE), Recife - PE. Brasil. Doutor em Psicologia pela Pontifícia Universidade Católica de São Paulo (PUC-SP), São Paulo - SP. Brasil.

E-mail: deoliveirafilhopedro@gmail.com

(iD https://orcid.org/0000-0003-2401-8953

Alessandra Aniceto Ferreira de Figueirêdo

Doutoranda em Saúde Coletiva pela Universidade Estadual do Rio de Janeiro (UERJ). Rio de Janeiro - RJ. Brasil. Mestre em Psicologia pela Universidade Federal de Pernambuco (UFPE), Recife - PE. Brasil.

E-mail: alessandra_aniceto@yahoo.com.br

(iD https://orcid.org/0000-0003-2156-9055

Endereço para envio de correspondência:

Rua Dr. Carlos Macieira, 73. Bairro JK. CEP: 58187-000. Picuí-PB.

Recebido 18/09/2017

Revisado 09/07/2018

Aceito 30/07/2018

Received 09/18/2017

Reformulated 07/09/2018

Approved 07/30/2018

Recibido 18/09/2017

Reformulado 09/07/2018

Aceptado 30/07/2018 
Henriques, H.I.B.; Oliveira Filho, P.; Figueiredo, A.A. F. (2019). O Vocabulário Religioso de Evangélicos Usuários de CAPS.

Como citar: Henriques, H. I., Oliveira Filho, P., Figueiredo, A.A. F. (2019). Um estudo sobre o vocabulário religioso utilizado por evangélicos usuários de CAPS. Psicologia: Ciência e Profissão, 39, 1-13.

https://doi.org/10.1590/1982-3703003185467

How to cite: Henriques, H. I., Oliveira Filho, P., Figueiredo, A.A. F. (2019). A study about religious vocabulary used by evangelical CAPS users. Psicologia: Ciência e Profissão, 39, 1-13. https://doi.org/10.1590/1982-3703003185467

Cómo citar: Henriques, H. I., Oliveira Filho, P., Figueiredo, A.A. F. (2019). Un estudio sobre el vocabulario religioso utilizado por evangélicos usuarios del CAPS. Psicologia: Ciência e Profissão, 39, 1-13.

https://doi.org/10.1590/1982-3703003185467 